\section{Being a Chameleon}

\author{
Geon Ho Bahn \\ Editor-in-Chief, Korean Academy of Child and Adolescent Psychiatry
}

Enormous changes are taking place at lightning speed in many areas beyond imagination: blockchain, the Internet of Things (IoT), autonomous vehicles, drone delivery, SmartFarm, artificial intelligence (AI) in science and economy, wearable healthcare devices, and robotic surgery in medicine. The ancient Chinese strategy game of Go used to be exclusively played by humans. They now, however, continually lose to AI players. Child psychiatry is no exception, either vertically or horizontally. Particularly, "Disorders Usually First Evident in Infancy, Childhood, or Adolescence" categorized in DSM-III and DSM-IV [1,2] became known as "Neurodevelopmental Disorders" in DSM-5 [3]. Child psychiatry may need to address the continuum of mental conditions as they may manifest at different stages of life from infancy to late adulthood. The Korean Academy of Child and Adolescent Psychiatry (KACAP) has prepared for this transition. As mentioned in Young Sik Lee's guest editorial [4], KACAP organized a subgroup known as the "Adult ADHD Special Interest Group (AASIG)" to develop the Korean assessment tools for adults with ADHD and complete the practice parameter for intervention, which has been published in this issue [5]. As part of the preparation process for the practice parameter, AASIG surveyed the current practice for ADHD in adults from psychiatrists in Korea. The results were published in the previous volume [6]. In addition, AASIG developed and published the Korean Adult ADHD Rating Scale [7]. AASIG will report the results of the application of the Korean version of the Diagnostic Interview for ADHD in Adults-5 (DIVA-5), as well as the efficacy study of the cognitive function assessment tool, Computerized Korean Comprehensive Attention Test (CAT). To better understand ADHD as a neurodevelopmental disorder, AASIG will continue to engage with general psychiatrists.

Crossing the boundaries of academic territory between pediatric psychiatry and related areas has occurred widely and very quickly. One of them is targeted on biomarkers for childhood mental disorders. Alexey Tinkov's “Magnesium status in children with attention-deficit/hyperactivity disorder and/

This is an Open Access article distributed under the terms of the Creative Commons Attribution Non-Commercial License (https://creativecommons.org/licenses/by-nc/4.0) which permits unrestricted non-commercial use, distribution, and reproduction in any medium, provided the original work is properly cited. or autism spectrum disorder" published in this issue [8] is also a study that seeks to find a biological origin of ADHD. Translational research also takes place in terms of culture and research subjects. In Subin Park's "Suicide attempts of South and North Korean-family youth and contributing factors using the Korean youth risk behavior web-based survey," the study involved adolescents who had parent(s) of North Korean origin, rarely exposed to clinical research [9]. Eunjoo Kim's “The use of virtual reality in psychiatry: a review" introduced a training program that enhances the attention span, academic skill, and social adaptability in a virtual classroom situation [10]. This is the evidence of a new attempt to break down and collaborate between the different specialties. Two books introduced by Hanik K. Yoo [11], namely "The Learning Brain" and "Essentials of Working Memory Assessment and Intervention" [12,13], also highlighted the need for translational research in the area of pediatric psychiatry and cognitive neuroscience.

The year 2020 is the 31st anniversary of the Journal of the Korean Academy of Child and Adolescent Psychiatry (JKACAP) foundation. What JKACAP intends to do remains to be the question at hand. A human being's 30s is the time for expansion and increase of intimacy through third separation individuation [14]. JKACAP should create a new identity based on the experience and wisdom of the past 30 years. The chameleon evolves to change its body color according to environmental changes for survival. Similarly, the JKACAP evolves to change its identity not only to survive, but to jump far ahead. The journal will also contribute to helping pediatric mental health professionals cultivate the capacity they need to usher in a new era.

\section{REFERENCES}

1) American Psychiatric Association. Diagnostic and statistical manual of mental disorders. 3rd ed. Washington DC: American Psychiatric Association; 1980

2) American Psychiatric Association. Diagnostic and statistical manual of mental disorders. 4th ed. Washington DC: American Psychiatric Association; 1994.

3) American Psychiatric Association. Diagnostic and statistical manual of mental disorders. 5th ed. Arlington (VA): American Psychiatric Association;2013.

4) Lee YS. The past four years research work of the adult attention-def- 
icit/hyperactivity disorder special interesting group in Korean Academy of Child and Adolescent Psychiatry. J Korean Acad Child Adolesc Psychiatry 2020;31:3-4.

5) Bahn GH, Lee YS, Yoo HK, Kim EJ, Park S, Han DH, et al. Development of the Korean practice parameter for adult attention-deficit/hyperactivity disorder. J Korean Acad Child Adolesc Psychiatry 2020;31:5-25.

6) Hong M, Lee S, Lee YS, Kim B, Joung YS, Yoo HK, et al. Comparison of attention-deficit/hyperactivity disorder practice in adults according to a training background in child psychiatry. J Korean J Korean Acad Child Adolesc Psychiatry 2019;30:121-126.

7) Hong M, Lee YS, Kim B, Joung YS, Yoo HK, Kim EJ, et al. Clinical utility and cut-off scores of the Korean adult attention-deficit/hyperactivity disorder rating scale. J Korean Acad Child Adolesc Psychiatry 2019;30:116-120.

8) Skalny AV, Mazaletskaya AL, Ajsuvakova OP, Bjørklund G, Skalnaya MG, Chernova LN, et al. Magnesium status in children with attention-deficit/hyperactivity disorder and/or autism spectrum disorder.
J Korean Acad Child Adolesc Psychiatry 2020;31:41-45.

9) Rim SJ, Lee MG, Park S. Suicide attempts and contributing factors among South and North Korean-family youth using the Korean youth risk behavior web-based survey. Korean Acad Child Adolesc Psychiatry 2020;31:33-40.

10) Kim S, Kim E. The use of virtual reality in psychiatry: a review. J Korean Acad Child Adolesc Psychiatry 2020;31:26-32.

11) Yoo HK. Two books on working memory. J Korean Acad Child Adolesc Psychiatry 2020;31:46-47.

12) Klingberg T. The larning brain: memory and brain development in children. New York (NY): Oxford University Press;2013.

13) Dehn MJ. Essentials of working memory assessment and intervention. Hobokin (NJ): John Wiley \& Sons Inc;2015 (Kaufman AS, Kaufman NL, editors. Essentials of psychological assessment series).

14) Bahn GH. What and how do psychotherapists consider the developmental stages in adult psychotherapy? Psychoanalysis 2019;30:79-88. 